\title{
Laboratory Study of the Ultraviolet Radiation Effect on an HDPE Geomembrane
}

\author{
Fernando Luiz Lavoie ${ }^{1,2}, * \mathbb{C}$, Marcelo Kobelnik ${ }^{2}$, Clever Aparecido Valentin ${ }^{2} \mathbb{D}$, Érica Fernanda da Silva Tirelli ${ }^{1}$, \\ Maria de Lurdes Lopes ${ }^{3}$ and Jefferson Lins da Silva ${ }^{2}$
}

1 Department of Civil Engineering, Mauá Institute of Technology, São Caetano do Sul 09580-900, Brazil; erica.tirelli@maua.br

2 São Carlos School of Engineering, University of São Paulo-USP, São Paulo 13566-590, Brazil; mkobelnik@gmail.com (M.K.); cclever@sc.usp.br (C.A.V.); jefferson@sc.usp.br (J.L.d.S.)

3 CONSTRUCT-GEO, Department of Civil Engineering, University of Porto, 4200-465 Porto, Portugal; lcosta@fe.up.pt

* Correspondence: fernando.lavoie@maua.br; Tel.: +55-119-8105-8718

Citation: Lavoie, F.L.; Kobelnik, M.; Valentin, C.A.; Tirelli, É.F.d.S.; Lopes, M.d.L.; Silva, J.L.d. Laboratory Study of the Ultraviolet Radiation Effect on an HDPE Geomembrane. Membranes 2021, 11, 390. https://doi.org /10.3390/membranes11060390

Academic Editor: Isabel C. Escobar

Received: 18 May 2021

Accepted: 23 May 2021

Published: 26 May 2021

Publisher's Note: MDPI stays neutral with regard to jurisdictional claims in published maps and institutional affiliations.

Copyright: (c) 2021 by the authors. Licensee MDPI, Basel, Switzerland. This article is an open access article distributed under the terms and conditions of the Creative Commons Attribution (CC BY) license (https:// creativecommons.org/licenses/by/ $4.0 /)$.

\begin{abstract}
High-density polyethylene (HDPE) geomembranes are polymeric geosynthetic materials usually applied as a liner in environmental facilities due to their good mechanical properties, good welding conditions, and excellent chemical resistance. A geomembrane's field performance is affected by different conditions and exposures, including ultraviolet radiation, thermal and oxidative exposure, and chemical contact. This article presents an experimental study with a $1.0 \mathrm{~mm}$-thick HDPE virgin geomembrane exposed by the Xenon arc weatherometer for $2160 \mathrm{~h}$ and the ultraviolet fluorescent weatherometer for $8760 \mathrm{~h}$ to understand the geomembrane's behavior under ultraviolet exposure. The evaluation was performed using the melt flow index (MFI) test, oxidative-induction time (OIT) tests, tensile test, differential scanning calorimetry (DSC) analysis, and Fourier transform infrared spectroscopy (FTIR) analysis. The sample exposed in the Xenon arc equipment showed a tendency to increase the MFI values during the exposure time. This upward trend may indicate morphological changes in the polymer. The tensile behavior analysis showed a tendency of the sample to lose ductility, without showing brittle behavior. The samples' OIT test results under both device exposures showed faster antioxidant depletion for the standard OIT test than the high-pressure OIT test. The DSC and FTIR analyses did not demonstrate the polymer's changes.
\end{abstract}

Keywords: high-density polyethylene; geomembrane; ultraviolet radiation; durability; thermal analysis

\section{Introduction}

Geomembranes are polymeric geosynthetic material used as a barrier in environmental facilities, such as landfills, mining facilities, and leachate ponds. This product is also utilized in waste liquid ponds, water ponds, farm ponds, adduction, and irrigation canals [1-3]. High-density polyethylene (HDPE) geomembranes are usually used as liners in environmental construction work due to good mechanical properties, good welding conditions, and excellent chemical resistance [4].

An HDPE geomembrane's field performance is affected by different conditions and exposures, including ultraviolet radiation, thermal and oxidative exposure, and chemical contact. These exposures can change the polyethylene's morphology, causing a reaction between the polymer chain with the oxygen molecule. Accelerated laboratory tests and exhumed sample evaluations indicate essential responses for the durability issue [5-7].

The synergy between ultraviolet (UV) radiation and thermal exposure leads to the geomembrane's lifetime [8,9]. The wavelength of solar radiation extends from the infrared (higher than $700 \mathrm{~nm}$ ), through the visible spectrum (400 to $700 \mathrm{~nm}$ ), and into the ultraviolet (lower than $400 \mathrm{~nm}$ ). A series of free radical reactions control the polyolefin's degradation. Polymer chain scission and polymer property degradation can occur when UV radiation 
reaches the geomembrane surface [10]. To protect the polymer from UV radiation, carbon black is added to the resin during the manufacturing process, about 2 to $3 \%$ in mass, typically with a particle size of $22-25 \mathrm{~nm}[2,10]$.

There are different methods to study the ultraviolet radiation effects on HDPE geomembranes, as the outside natural radiation exposure demands long-term evaluation, and by the laboratory, using weatherometers [10]. The evaluation of ultraviolet radiation on HDPE geomembranes at the laboratory can be proceeded by different weatherometers: Xenon arc or an ultraviolet fluorescent tube device. Xenon arc weatherometer use in the geosynthetics field is remote due to the high cost involved [11].

Sahu et al. [12] evaluated the influence of ultraviolet light on the thermal properties of HDPE for different carbon black concentrations from 1 to $3 \%$. The authors used an ultraviolet fluorescent weatherometer for a cycle of $192 \mathrm{~h}$. The Fourier transform infrared spectroscopy (FTIR) and differential scanning calorimetry (DSC) were used to analyze the HDPE behavior before and after UV exposure. The analysis confirms that the carbon black was evenly dispersed without degradation in the HDPE matrix.

Jiang et al. [13] investigated an HDPE resin after $800 \mathrm{~h}$ of exposure in a Xenon arc lamp device. Antioxidants and a UV absorber were added to understand their influences on ultraviolet resistance. The authors performed FTIR, DSC, and TG (thermogravimetric) analyses and the mechanical test. The results showed which UV absorbers presented better results than the antioxidants. The samples with UV absorbers added maintained their mechanical properties even after $600 \mathrm{~h}$ of exposure.

The field study provided by Reis et al. [14] evaluated five $2.0 \mathrm{~mm}$-thick high-density polyethylene geomembrane samples exposed in 8 different places in Portugal over 12 years. The samples presented slight variations in the tensile properties, increasing elongation properties, which was not explained by the authors. Locations with higher UV indexes suggest an impact on tensile properties and antioxidant depletion.

The changes in the structural properties of high-density polyethylene film exposed to UV-B radiation were studied by Martínez-Romo et al. [15]. The crystalline phase fraction of high-density polyethylene film increased further after 30 days of exposure to UV-B radiation, affecting the physical properties such as stiffness, dissolution resistance, and dimensional stability. The results showed which sample had a high oxidation degree.

Mendes et al. [16] analyzed HDPE samples with and without additives exposed to weathering in Rio de Janeiro, Brazil, up to $4000 \mathrm{~h}$. The additives utilized were a phenol type antioxidant and two HALS-type light stabilizers. The authors used FTIR analysis, DSC analysis to determine the crystallinity, mechanical tests, and the variation of the sample's molecular weight was evaluated by gel permeation chromatography. The results showed decreased elongation at break for the sample without additives, demonstrating the almost total loss in ductility. The increase in crystallinity and reduction of molecular weight for the sample without additives was still verified. The sample stabilized with the additives remained constant for the exposure time, demonstrating the additives' effectiveness.

Qureshi et al. [17] evaluated a linear low-density polyethylene (LLDPE) geomembrane with $3.0 \mathrm{~mm}$ of thickness without stabilizers under weather exposure in Saudi Arabia. After three months of exposure, the geomembrane presented losses higher than $50 \%$ in the tensile properties.

A 16-year-old HDPE geomembrane exhumed from a mining facility in a freshwater pond in Argentina and a 6-year-old HDPE geomembrane exhumed from an environmental liner test site in Canada (both samples were $1.5 \mathrm{~mm}$ thick) were evaluated using the OIT test by Rowe and Ewais [18]. The exhumed sample, after 16 years of service, presented complete antioxidant depletion. The exhumed sample from the research site performed well, presenting a modest antioxidant depletion. The antioxidant depletion for the research site was faster for the slope location than the bottom location.

Lavoie et al. [19] used thermal analysis to evaluate a $1.0 \mathrm{~mm}$ thick HDPE geomembrane exhumed sample from an industrial water pond after up to 2 years of service. Comparing the exhumed sample with a virgin reference sample, the heating rate of $5{ }^{\circ} \mathrm{C} \mathrm{min}-1$ at 
the TG analysis noted a different behavior for the exhumed sample, attributed to the reaction time. For the thermomechanical analysis (TMA), the molecular relaxation between 30-65 ${ }^{\circ} \mathrm{C}$ verified for the reference sample was not noted for the exhumed sample. According to the authors, these differences can indicate changes in the polymer morphology.

HDPE geomembranes are usually applied as a pond liner outdoors for the entire service life. This work evaluated a high-density polyethylene smooth geomembrane sample that was $1.0 \mathrm{~mm}$ thick, often used for geotechnical, environmental, and agricultural applications, exposed by the Xenon arc weatherometer for $2160 \mathrm{~h}$ (90 days) in the shortterm of accelerated laboratory exposure, and the ultraviolet fluorescent weatherometer in the short-term, medium-term, and long-term for 8760 h (365 days) of accelerated laboratory exposure to understand the geomembrane's behavior under ultraviolet exposure. This work compared the geomembrane's behavior between different ultraviolet devices for shortterm exposure, provided new data for the Xenon arc device exposure for the geosynthetics study, and also provided new data for both the DSC analysis and FTIR analysis for HDPE geomembranes after laboratory exposure. The evaluation was performed using the MFI test, OIT tests, tensile test, DSC analysis, and FTIR analysis.

\section{Materials and Methods}

\subsection{HDPE Geomembrane and Accelerated Weathering Tests}

The present work analyzed an HDPE smooth geomembrane with $1.0 \mathrm{~mm}$ of nominal thickness manufactured in Brazil. The material was produced by the extrusion-blown film process and formulated with $96-97.5 \%$ of medium-density polyethylene (density $\geq 0.940 \mathrm{~g} \mathrm{~cm}^{-3}$ ), $2-3 \%$ of carbon black and $0.5-1.0 \%$ of antioxidants and thermostabilizers [20]. The geomembrane's roll has dimensions of $5.90 \mathrm{~m}$ of width and $100 \mathrm{~m}$ of length. Table 1 shows the samples' initial properties.

Table 1. Initial values of high-density polyethylene geomembrane's properties.

\begin{tabular}{cccc}
\hline Property & Method & Unit & Mean Value \\
\hline Thickness & ASTM D5199 [21] & $\mathrm{mm}^{-3}$ & $1.040( \pm 0.079)$ \\
Density & ASTM D792 [22] & $\mathrm{g} \mathrm{cm}^{-3}$ & $0.958( \pm 0.002)$ \\
MFI $\left(5.0 \mathrm{~kg} / 190^{\circ} \mathrm{C}\right)$ & ASTM D1238 [23] & $\mathrm{g} 10 \mathrm{~min}^{-1}$ & $0.6800( \pm 0.0217)$ \\
Carbon black content & ASTM D4218 [24] & $\%$ & $3.14( \pm 0.13)$ \\
Carbon black dispersion & ASTM D5593 [25] & Category & Category I \\
Tensile break resistance & ASTM D6693 [26] & $\mathrm{kN} \mathrm{m}^{-1}$ & $28.52( \pm 1.55)$ \\
Tensile break elongation & ASTM D1004 [27] & $\mathrm{N}$ & $733.47( \pm 10.76)$ \\
Tear resistance & ASTM D4833 [28] & $\mathrm{N}$ & $169.17( \pm 8.76)$ \\
Puncture resistance & ASTM D5397 [29] & $\mathrm{h}$ & $434.17( \pm 18.19)$ \\
Stress crack resistance & ASTM D3895 [30] & $\mathrm{min}$ & $16.47( \pm 2.66)$ \\
Standard OIT & ASTM D5885 [31] & $\mathrm{min}$ & $40.49( \pm 0.73)$ \\
High-pressure OIT & & & $125.70( \pm 0.42)$ \\
\hline
\end{tabular}

Standard deviations are between brackets.

The GRI-GM13 [32] is an American standard specification for HDPE smooth and textured geomembrane manufacturing quality control. This sample showed a carbon black content slightly higher than the required value range (2-3\%), stress crack resistance lower than the minimum required value $(500 \mathrm{~h})$, and lower than the OIT minimum value required for the OIT (100 min for the Standard OIT and $400 \mathrm{~min}$ for the High Pressure OIT).

A UV-weathering chamber was used from Equilam at Diadema, Brazil, model EQUV, with fluorescent UVA-340 lamps, manufactured by Philips, programmed to work in cycles of $20 \pm 0.01 \mathrm{~h}$ of $\mathrm{UV}$ light at $75 \pm 1^{\circ} \mathrm{C}$ followed by $4 \pm 0.01 \mathrm{~h}$ of condensation at $50 \pm 0.01{ }^{\circ} \mathrm{C}$ for periods of 960,4380 , and $8760 \pm 0.01 \mathrm{~h}$. As a reference, the standard test method used was described by ASTM D7238 [33]. Moreover, the Xenon arc chamber used was from Q-Lab in Cleveland, USA, model Xe-3-HS, with UVA-340 fluorescent lamps, manufactured by Philips. The equipment was programmed to operate in $102 \pm 0.01$ min cycles with a black panel temperature of $60 \pm 1{ }^{\circ} \mathrm{C}$ followed by $18 \pm 0.01 \mathrm{~min}$ of light and water spray 
for periods of 960,1639 , and $2160 \mathrm{~h} \pm 0.01 \mathrm{~h}$. As a reference, the standard test method used was described by ASTM G155 [34].

\subsection{Melt Flow Index (MFI) Test}

The melt flow index test [23] was carried out using a plastometer manufactured by Instron at Norwood, USA, model CEAST MF20. The material was extruded through a smooth bore $(2.095 \pm 0.005 \mathrm{~mm}$ in diameter and $8000 \pm 0.025 \mathrm{~mm}$ long $)$ at $190 \pm 0.08^{\circ} \mathrm{C}$ with a $5.0 \pm 0.01 \mathrm{~kg}$ of deadweight. After $10 \pm 0.01 \mathrm{~min}$ of the sample extrusion, the material mass was measured using an analytical balance with $0.0001 \mathrm{~g}$ of precision.

\subsection{Tensile Properties}

The tensile test [26] was performed using a universal machine, manufactured by EMIC at São José dos Pinhais, Brazil, model DL 3000, equipped with a 2-kN load cell and pneumatic grips. The material was tested only for the machine direction and the analysis was realized for the tensile at break. A test speed of $50 \pm 0.05 \mathrm{~mm} \mathrm{~min}^{-1}$ and the IV dog bone specimen were used. This test was conducted only for the aged samples from the UV-weathering chamber. The aged samples from the Xenon arc chamber did not present an adequate size to conduct this test.

\subsection{Oxidative-Induction Time (OIT) Tests}

The oxidative-induction time (OIT) was performed for the standard test (Std. OIT) [30] and high-pressure test (HP OIT) [31], using DSC equipment, model Q20, manufactured by TA Instruments in New Castle, USA, and an aluminum crucible (sample mass of $5 \pm 0.5 \mathrm{mg}$ ). These tests were conducted in two phases: the endothermic reaction using nitrogen gas purge followed by the specimen oxidation. The standard test was conducted at $200 \pm 2{ }^{\circ} \mathrm{C}$ with a constant oxygen pressure of $140 \pm 5 \mathrm{kPa}$, a heating rate of $20 \pm 1{ }^{\circ} \mathrm{C} \mathrm{min}{ }^{-1}$ and flow rate of $50 \pm 5 \mathrm{~mL} \mathrm{~min}^{-1}$. The high-pressure test was conducted at $150 \pm 0.5^{\circ} \mathrm{C}$ with a heating rate of $20 \pm 1{ }^{\circ} \mathrm{C} \mathrm{min}-1$ and a constant oxygen pressure of $3.4 \pm 0.06 \mathrm{MPa}$.

\subsection{Differential Scanning Calorimetry (DSC) Analysis}

The analysis was conducted using a nitrogen gas purge with a flow of $50 \pm 5 \mathrm{~mL} \mathrm{~min}^{-1}$, an aluminum crucible with a sample mass of $5 \pm 0.5 \mathrm{mg}$, a heating rate of $10 \pm 1{ }^{\circ} \mathrm{C} \mathrm{min}{ }^{-1}$, and a temperature range of 25 to $200 \pm 2{ }^{\circ} \mathrm{C}$. The DSC equipment used was manufactured by TA Instruments at New Castle, USA, model Q20.

\subsection{Fourier Transform Infrared Spectroscopy (FTIR) Analysis}

The FTIR analysis was carried out using a spectrometer manufactured by Thermo Scientific at Waltham, USA, model Nicolet iS10, with a wavenumber range of $400-4000 \pm 4 \mathrm{~cm}^{-1}$. The samples were analyzed in spectra using the attenuated total reflectance (ATR) technique. This technique is used to obtain good quality spectra in solid materials, which must be in perfect contact with the crystal. The conditions for recording the spectra were 16 sweeps and a scan resolution of $4.0 \mathrm{~cm}^{-1}$, a sweep speed of $0.20 \pm 0.01 \mathrm{~cm} \mathrm{~s}^{-1}$ at $20 \pm 1^{\circ} \mathrm{C}$. The spectrum was obtained using the OMNIC program. The absorption bands and peak intensity were obtained using the function "find peaks".

\section{Results and Discussion}

\subsection{Melt Flow Index (MFI) Test Results}

Table 2 presents the results of the MFI tests after ultraviolet exposure in the laboratory. Figure 1 shows the behavior of the samples in percent for the two laboratory exposure devices retained from the property. It can be observed that for the exposure in the Xenon arc chamber, the sample showed continuous growth in the melt flow index during the exposure times. On the other hand, the sample under exposure by the UV fluorescent device showed variations in the results of the MFI tests during the exposure times. 
Table 2. MFI test results after UV laboratory exposures.

\begin{tabular}{cccc}
\hline Sample & Exposure Time (h) & MFI (g min $\mathbf{~}^{\mathbf{1})}$ & MFI (\%) \\
\hline Virgin & 0 & $0.6800( \pm 0.0217)$ & 100.0 \\
UV fluorescent & 960 & $0.7094( \pm 0.0460)$ & 104.33 \\
UV fluorescent & 4380 & $0.6275( \pm 0.0369)$ & 92.29 \\
UV fluorescent & 8760 & $0.6991( \pm 0.0594)$ & 102.81 \\
Xenon arc & 960 & $0.6958( \pm 0.0161)$ & 102.33 \\
Xenon arc & 1639 & $0.7437( \pm 0.0514)$ & 109.36 \\
Xenon arc & 2160 & $0.7677( \pm 0.0453)$ & 112.89 \\
\hline
\end{tabular}

Standard deviations are between brackets.

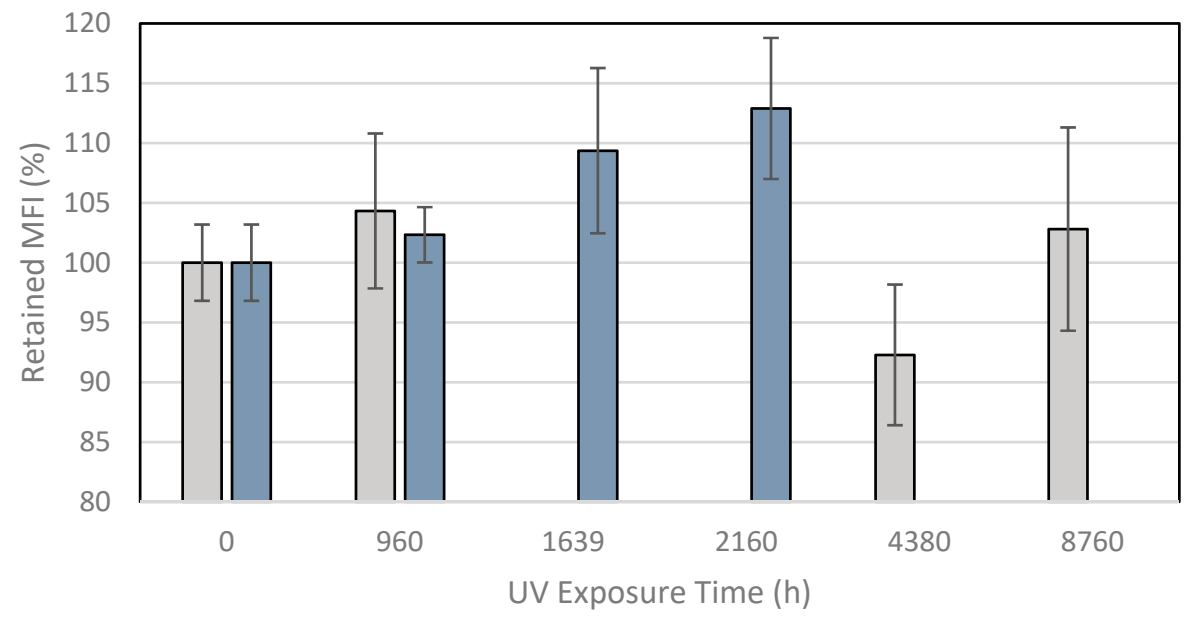

$\square$ UV Fluorescent $\square$ Xenon Arc

Figure 1. MFI test results showing behavior of the samples after UV exposures.

Many authors $[20,35,36]$ described an understanding of the melt flow index result behavior. Generally, a decrease in MFI test results can indicate an increase in molecular weight by cross-linking reactions; whereas, an increase in MFI can indicate a decrease in molecular weight due to chain scission reactions. The MFI is a qualitative test to assess the polymer's molecular weight. If the MFI value does not change after exposure, this method is not sufficient to understand the material behavior. In this case, both reactions (cross-linking and chain scission) could occur at the same time. Lodi et al. [20] evaluated the MFI test results of high-density polyethylene geomembranes after 30 months of weathering exposure in Brazil. The results showed an increase of up to $50 \%$ for the $2.5 \mathrm{~mm}$-thick sample and decreased to $15 \%$ for the $0.8 \mathrm{~mm}$-thick sample. According to the authors, the melt flow index results for the $2.5 \mathrm{~mm}$-thick geomembrane indicates chain scission.

The sample in the Xenon arc exposure chamber showed increases of 2, 9, and $13 \%$, respectively, for 960,1639 and $2160 \mathrm{~h}$ of exposure. The increasing trend can indicate changes in the polymer morphology. However, it was noted that the sample exposed in the UV fluorescent device showed variations between the virgin samples of $4,-8$, and $3 \%$, respectively, for 960,1639 , and $2160 \mathrm{~h}$ of exposure. In this case, there is no tendency to explain the behavior of the material. These variations are probably related to variation in the material's properties due to the manufacturing process and variation in exposure to the UV fluorescent device. The standard test method ASTM D7238 [33] prescribes the rotation of the samples in the UV fluorescent device every week to minimize variations among the samples. 


\subsection{Tensile Properties}

Table 3 presents the tensile test results at break for the UV fluorescent device exposure. Figure 2 shows the tensile behavior of the sample as a percentage retained from the property. The same behavior was noted for the resistance and elongation properties during the exposure time. The sample exhibited a tendency to lose ductility, without showing brittle behavior.

Table 3. Tensile at break test results after UV fluorescent device exposure.

\begin{tabular}{|c|c|c|c|c|}
\hline $\begin{array}{l}\text { Exposure Time } \\
\text { (h) }\end{array}$ & $\begin{array}{l}\text { Tensile Resist. } \\
\quad\left(\mathbf{k N ~ m}^{-1}\right)\end{array}$ & $\begin{array}{c}\text { Tensile Resist. } \\
\text { (\%) }\end{array}$ & $\begin{array}{c}\text { Tensile Elong. } \\
(\%)\end{array}$ & $\begin{array}{c}\text { Tensile Elong. } \\
(\%)\end{array}$ \\
\hline 0 & $28.52( \pm 1.55)$ & 100.0 & $733.47( \pm 10.76)$ & 100.0 \\
\hline 960 & $20.87( \pm 1.12)$ & 73.18 & $511.47( \pm 13.67)$ & 69.73 \\
\hline 4380 & $20.09( \pm 1.64)$ & 70.45 & $509.67( \pm 16.20)$ & 69.49 \\
\hline 8760 & $20.00( \pm 1.54)$ & 77.15 & $558.70( \pm 12.47)$ & 76.17 \\
\hline
\end{tabular}

Standard deviations are between brackets.

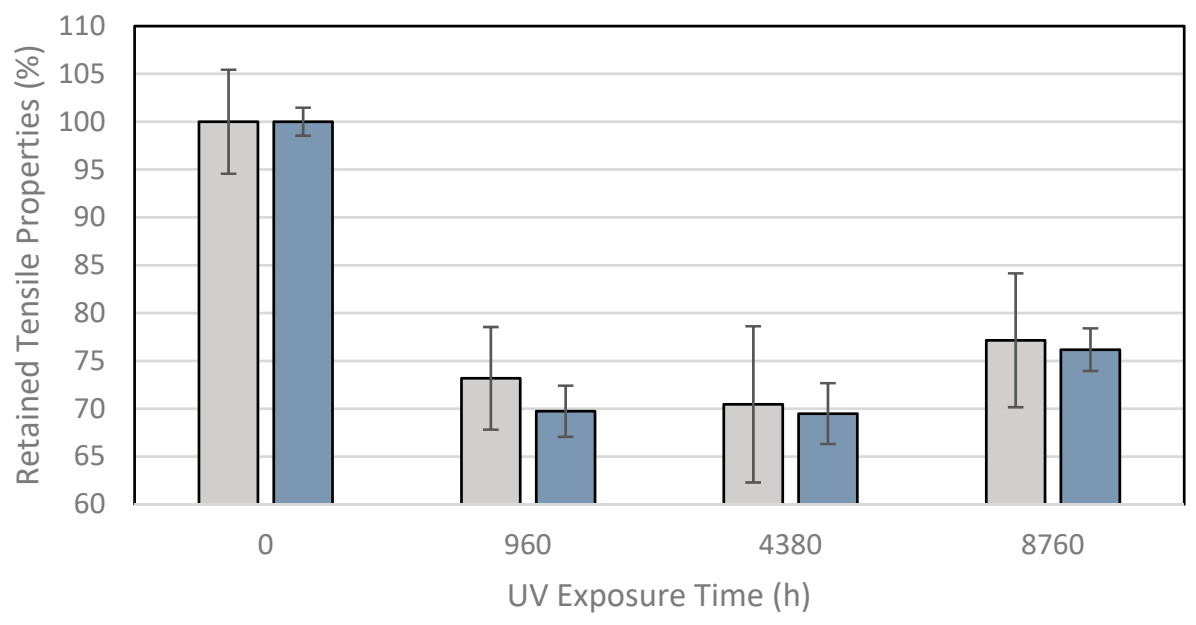

$\square$ Tensile Resistance $\quad \square$ Tensile Elongation

Figure 2. Tensile behavior of the samples after UV fluorescent device exposure.

Tensile properties were evaluated by Noval et al. [37] for an HDPE geomembrane with $1.5 \mathrm{~mm}$ of thickness during 20 years of weathering exposure in the San Isidro reservoir in Spain. The resistance and elongation presented the same trend during the time examined. The lowest values found were after 8 years of exposure, with decreases of around 45 and $60 \%$, respectively, for tensile strength and tensile elongation. After 20 years of exposure, the final evaluation showed decreases of about 25 and $35 \%$, respectively, for the tensile resistance and tensile elongation.

Lavoie et al. [19] noted the tensile brittle behavior tendency for a high-density polyethylene geomembrane with $1.0 \mathrm{~mm}$ of thickness after 2.25 years of weathering exposure in an industrial water pond in Brazil.

The sample under UV fluorescent device exposure presented decreases for the tensile resistance of 27,30 , and $23 \%$, respectively, for 960,4380 , and $8760 \mathrm{~h}$ of exposure. The sample presented decreases for the tensile elongation of 30, 31, and $24 \%$, respectively, for 960, 4380, and $8760 \mathrm{~h}$ of exposure. On average, the resistance and elongation decreased during the exposure times by around $30 \%$. 


\subsection{Oxidative-Induction Time (OIT) Test Results}

\subsubsection{Standard Oxidative-Induction Time (Std. OIT) Test Results}

Table 4 presents the Std. OIT test results after the ultraviolet exposures at the laboratory. Figure 3 shows the behavior of the sample for both laboratory exposure devices in percent retained from the property. The antioxidant depletion for both exposures can be observed. The fastest antioxidant depletion occurred for the Xenon arc exposure chamber considering that the exposure time was shorter than the exposure in the fluorescent UV device.

Table 4. Std. OIT test results after the UV laboratory exposures.

\begin{tabular}{cccc}
\hline Sample & Exposure Time (h) & Std. OIT (min) & Std. OIT (\%) \\
\hline Virgin & 0 & $40.49( \pm 0.73)$ & 100 \\
UV fluorescent & 960 & $37.63( \pm 3.30)$ & 92.94 \\
UV fluorescent & 4380 & $28.32( \pm 2.11)$ & 69.93 \\
UV fluorescent & 8760 & $11.30(( \pm 1.48)$ & 27.91 \\
Xenon arc & 960 & $34.15( \pm 1.27)$ & 84.33 \\
Xenon arc & 1639 & $28.40( \pm 0.93)$ & 70.13 \\
Xenon arc & 2160 & $24.88( \pm 2.04)$ & 61,45 \\
\hline
\end{tabular}

Standard deviations between brackets.

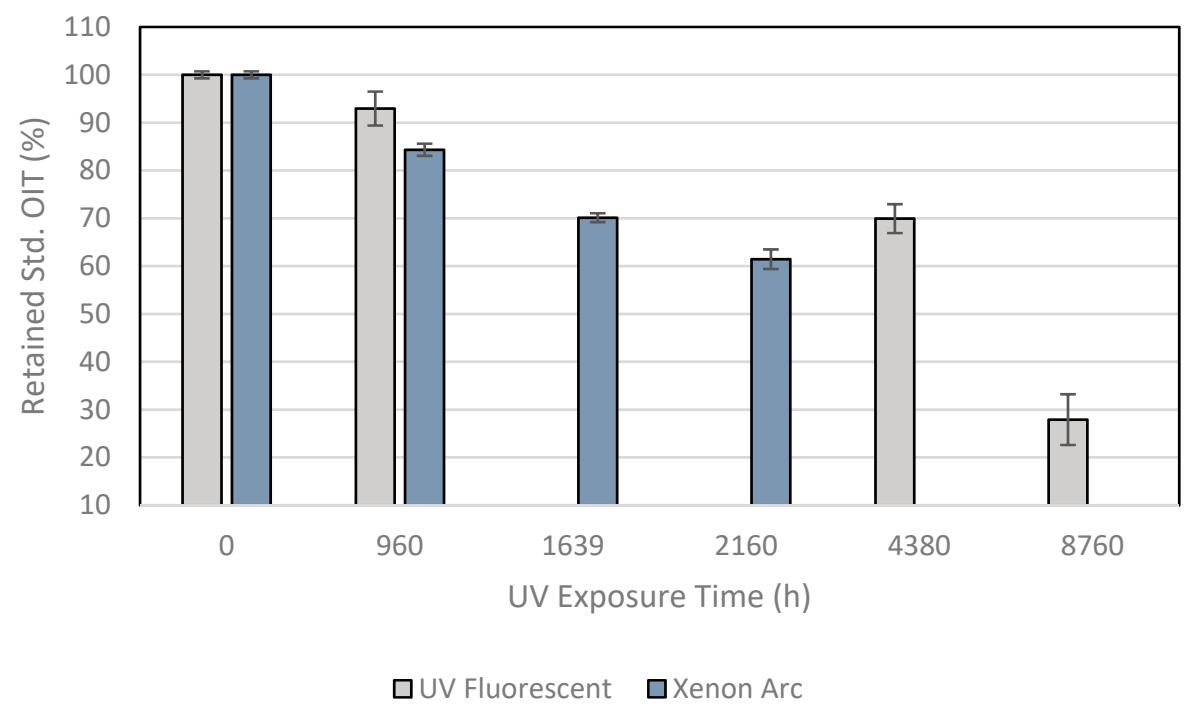

Figure 3. Std. OIT test results showing behavior of the samples after UV exposures.

Reis et al. [14] evaluated the Std. OIT results for two weathering exposure locations in Portugal. After 12 years of weathering exposure, the $2.0 \mathrm{~mm}$-thick geomembrane samples exposed at Bigorne and Viana de Castelo showed decreases of about 40 and $50 \%$, respectively.

The sample under exposure in the Xenon arc exposure chamber showed a decrease in OIT values of 16, 30, and 39\%, respectively, for 960, 1639, and $2160 \mathrm{~h}$ of exposure. The sample under UV fluorescent device exposure demonstrated decreases of 7, 30, and 72\%, respectively, for 960, 4380, and $8760 \mathrm{~h}$ of exposure. The comparison of the OIT values between the Xenon arc exposure chamber in $1639 \mathrm{~h}$ and the fluorescent UV exposure device in 4380 h showed approximately the same consumption of antioxidants, demonstrating that the fastest depletion rate of antioxidants was for the Xenon arc exposure chamber. The fast antioxidant depletion was noted for both exposure devices, demonstrating the ultraviolet radiation effect on the material's antioxidants. 


\subsubsection{High-Pressure Oxidative-Induction Time (HP OIT) Test Results}

Table 5 presents the HP OIT test results after the ultraviolet exposures in the laboratory. Figure 4 shows the behavior of the sample for the two laboratory exposure devices in percent retained from the property. Similar antioxidant depletion for both device exposures was noted.

Table 5. HP OIT test results after UV laboratory exposures.

\begin{tabular}{cccc}
\hline Sample & Exposure Time (h) & HP OIT (min) & HP OIT (\%) \\
\hline Virgin & 0 & $125.70( \pm 0.42)$ & 100 \\
UV fluorescent & 960 & $118.02( \pm 2.62)$ & 93.89 \\
UV fluorescent & 4380 & $103.09( \pm 2.13)$ & 82.01 \\
UV fluorescent & 8760 & $80.96( \pm 1.46)$ & 64.40 \\
Xenon arc & 960 & $124.69( \pm 0.86)$ & 99.20 \\
Xenon arc & 1639 & $119.17( \pm 2.10)$ & 94.80 \\
Xenon arc & 2160 & $114.83( \pm 1.20)$ & 91.35 \\
\hline
\end{tabular}

Standard deviations are between brackets.

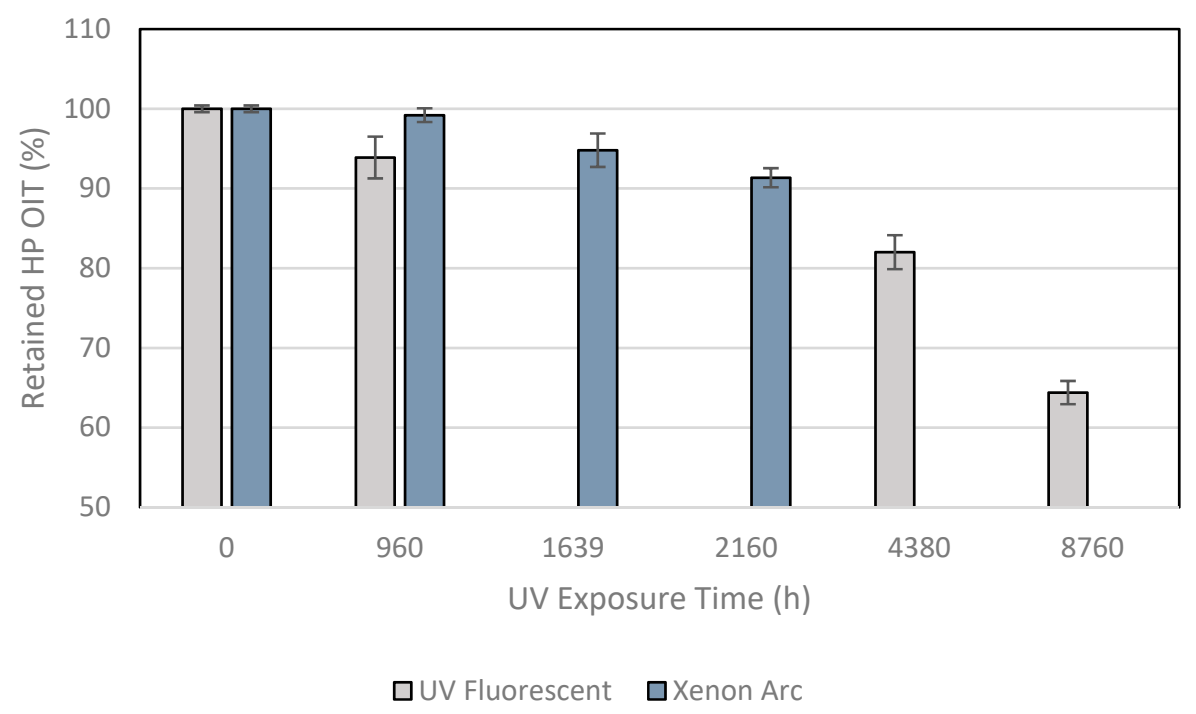

Figure 4. HP OIT test results showing behavior of the samples after UV exposures.

According to Hsuan et al. [35], the high-pressure OIT test can distinguish different types of antioxidants, and the test operation's temperature promotes a good relation to the service conditions.

The sample in the Xenon arc exposure chamber demonstrated decreases of $0.8,5$, and $9 \%$, respectively, for 960,1639 , and $2160 \mathrm{~h}$ of exposure. The sample under UV fluorescent device exposure demonstrated decreases of 6,18 , and $36 \%$, respectively, for 960,4380 , and $8760 \mathrm{~h}$ of exposure. A lower antioxidant depletion compared with the Std. OIT test was noted for both exposures.

\subsection{Differential Scanning Calorimetry (DSC) Analysis}

Figure 5 shows the samples' DSC curves of heating (A) and cooling (B). A curves' overlap adjustment was performed to coincide with the peaks. Initially, the samples were heated up to $200{ }^{\circ} \mathrm{C}$, where a peak attributed to the melting point was observed (Figure 5A). For all samples, the melting point essentially has the same behavior, without presenting any displacement or overlapping reactions due to the different exposure time of the samples analyzed. This behavior can be explained because the polymer under melting does not present crystallinity, predominating the disordered molecular material. The degraded molecules by ultraviolet radiation or other radiation are involved in the melting 
process, making it difficult to identify the degradation of the molecules. The crystallization of the different samples can be seen in Figure 5B. The crystallization process tends to ordinate the polymer's melted molecules, leading to an exothermic process. Thus, the molecules' degradation was hidden by the molecules' reorientation, obtaining coincident crystallization points at the DSC curves. The glass transition behavior depends on a cooling system and was not obtained in this work. This analysis is necessary for future evaluations.

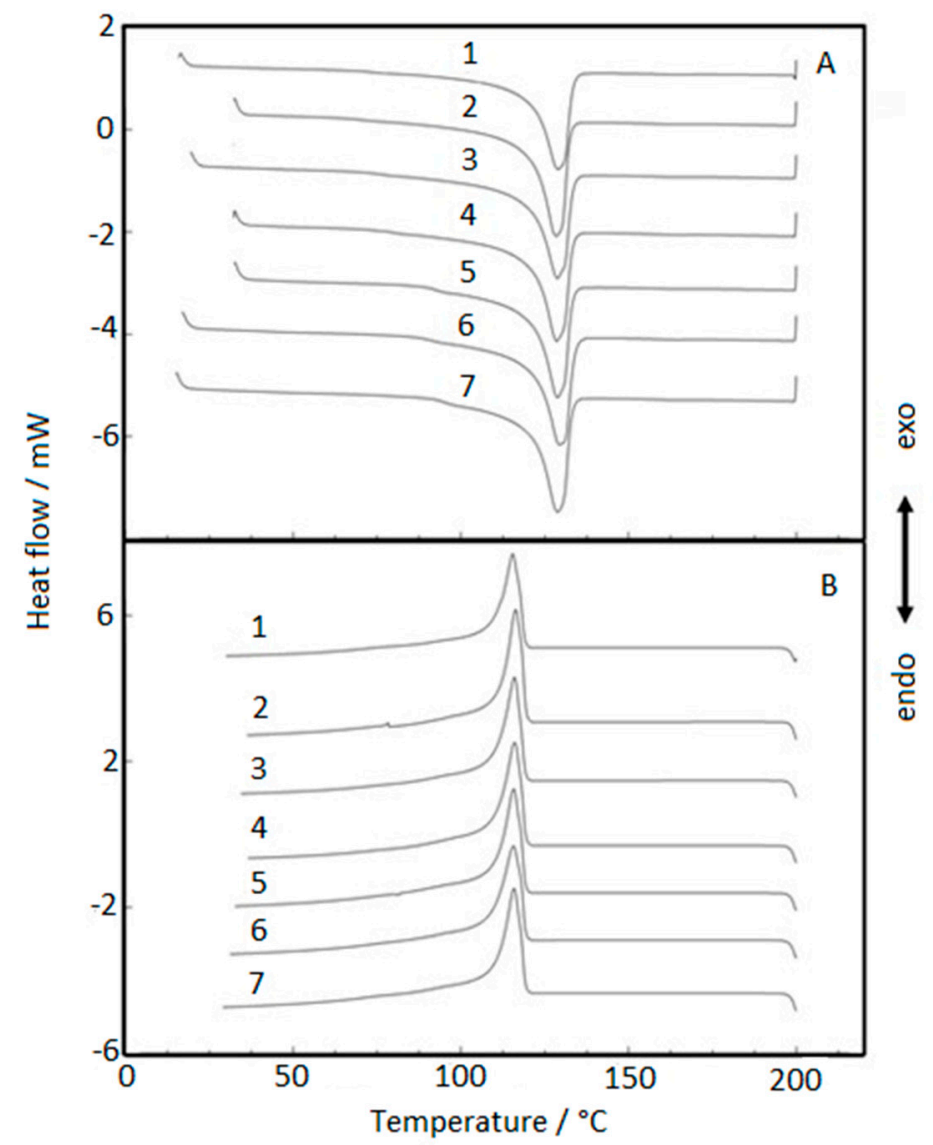

Figure 5. DSC curves: (A) melting point stage and (B) crystallization stage. 1-virgin sample; 2-960 h Xenon arc sample; 3-1639 h Xenon arc sample; 4-2160 h Xenon arc sample; 5-960 h UV fluorescent sample; 6-4380 h UV Fluorescent sample; and 7-8760 h UV fluorescent sample.

\subsection{Fourier Transform Infrared Spectroscopy (FTIR) Analysis}

Figure 6 shows the FTIR analysis for the UV fluorescent exposure device and the Xenon arc exposure chamber, highlighting the range from 600 to $3100 \mathrm{~cm}^{-1}$ to check the possibility of formations, breaks in the functional groups, and oxidative reactions. The analyzed samples are formed by repetitions of $\mathrm{CH}_{2}$ groups. Consequently, the appearance of absorbance bands characteristic of simple $\mathrm{C}-\mathrm{H}$ bonds and Covalent $\mathrm{C}-\mathrm{C}$ bonds is expected using this technique [38,39].

The three modes of the $\mathrm{C}-\mathrm{H}$ link vibration can be observed through the spectrum. The bands observed in the range of 2800 to $3000 \mathrm{~cm}^{-1}$ refer to axial deformations C-H (Figure 7). The angular vibration of $\mathrm{CH}_{2}$ was observed in the range of 1400 to $1500 \mathrm{~cm}^{-1}$ (Figure 8) and the bands referring to the asymmetric deformation of $\mathrm{CH}_{2}$ were noted in the region of 700-730 $\mathrm{cm}^{-1}$ (Figure 9) [39]. The low-intensity bands observed in the region between 1000-1250 $\mathrm{cm}^{-1}$ refer to the link's vibrations C-C (Figure 10) [40]. It was not possible to notice a significant variation in the obtained spectra, since the absorption intensities of the bands were close. 


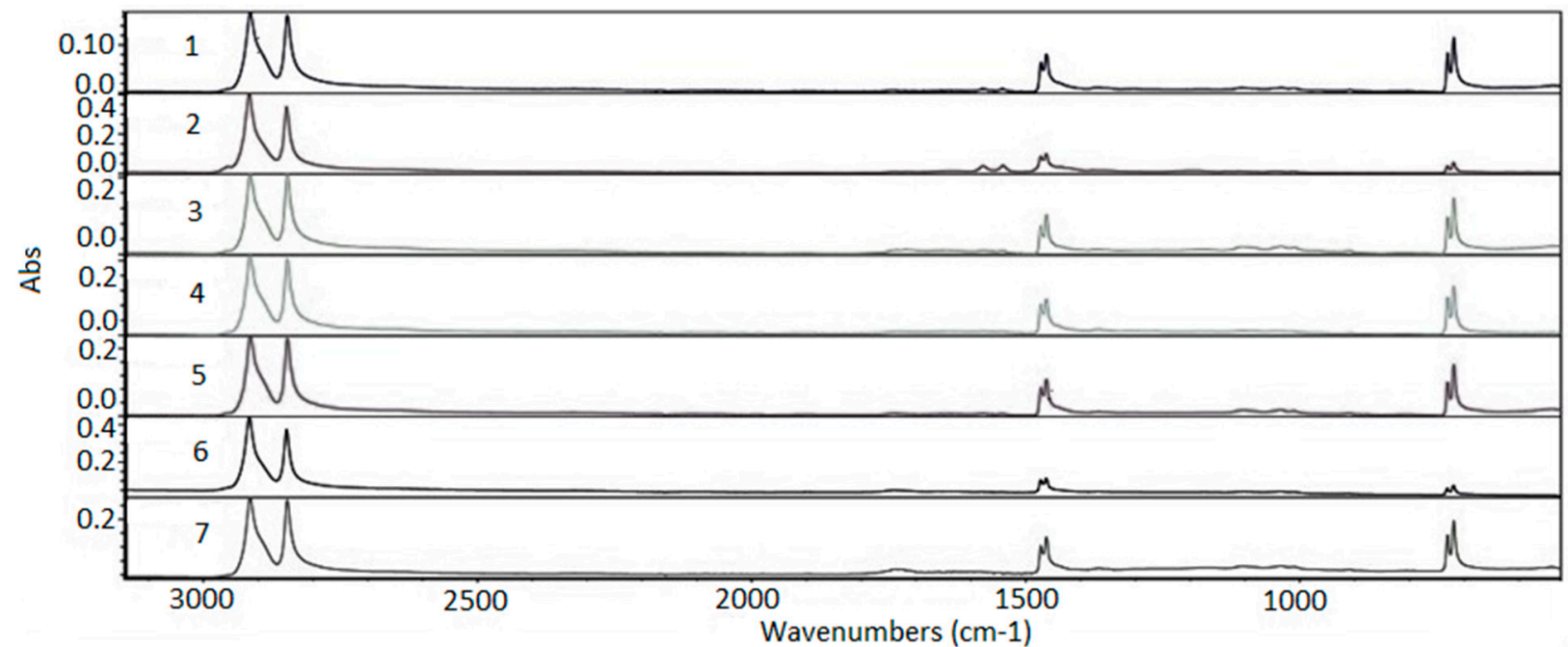

Figure 6. Absorption spectra region from 600 to $3100 \mathrm{~cm}^{-1}$. 1-virgin sample; 2-960 h Xenon arc sample; 3-1639 h Xenon arc sample; 4-2160 h Xenon arc sample; 5-960 h UV fluorescent sample; 6-4380 h UV fluorescent sample; and $7-8760 \mathrm{~h}$ UV fluorescent sample.

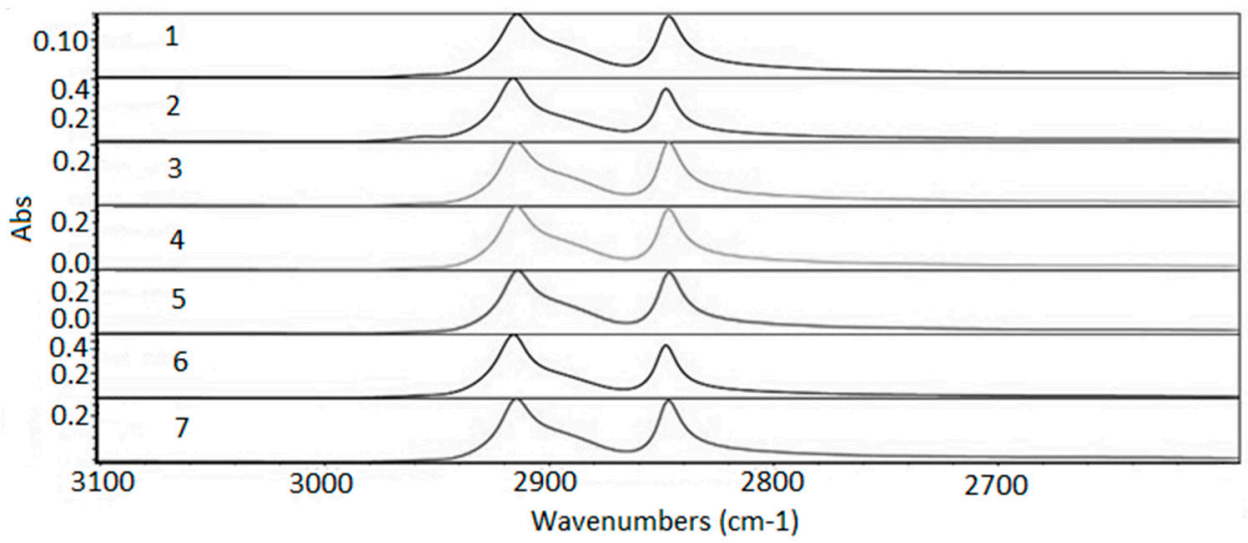

Figure 7. Absorption spectra region from 3100 to $2600 \mathrm{~cm}^{-1}$. 1-virgin sample; 2-960 h Xenon arc sample; 3-1639 h Xenon arc sample; 4-2160 h Xenon arc sample; 5-960 h UV fluorescent sample; 6-4380 h UV fluorescent sample; and 7-8760 h UV fluorescent sample.

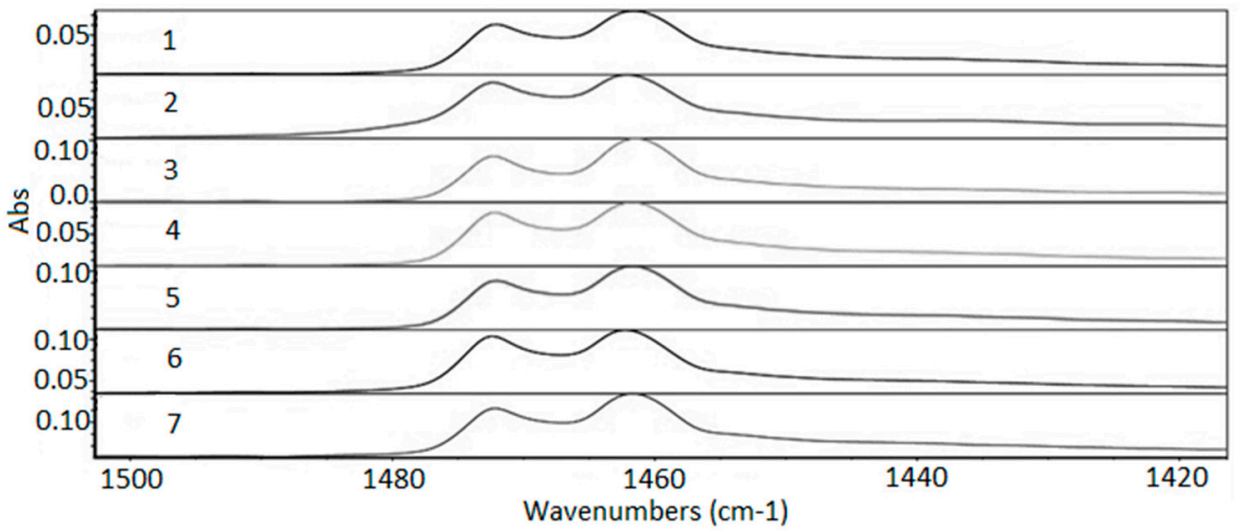

Figure 8. Absorption spectra region from 1420 to $1500 \mathrm{~cm}^{-1}$. 1-virgin sample; 2 - $960 \mathrm{~h}$ Xenon arc sample; 3-1639 h Xenon arc sample; 4-2160 h Xenon arc sample; 5-960 h UV fluorescent sample; 6-4380 h UV fluorescent sample; and 7-8760 h UV fluorescent sample. 


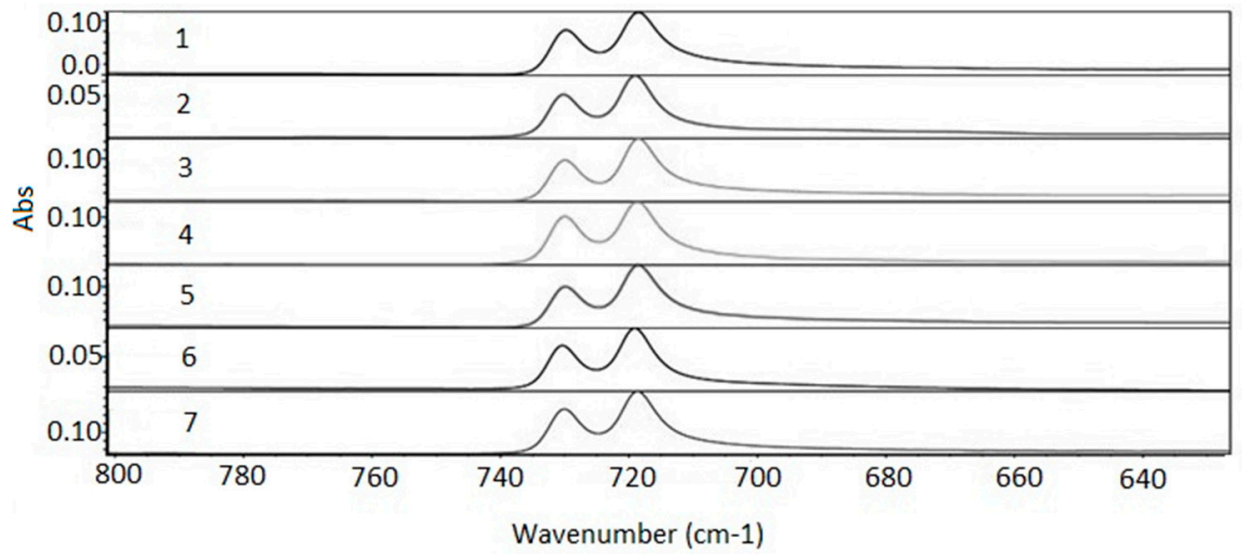

Figure 9. Absorption spectra region from 620 to $800 \mathrm{~cm}^{-1}$. 1-virgin sample; 2-960 h Xenon arc sample; 3-1639 h Xenon arc sample; 4-2160 h Xenon arc sample; 5-960 h UV fluorescent sample; 6-4380 h UV fluorescent sample; and 7-8760 h UV fluorescent sample.

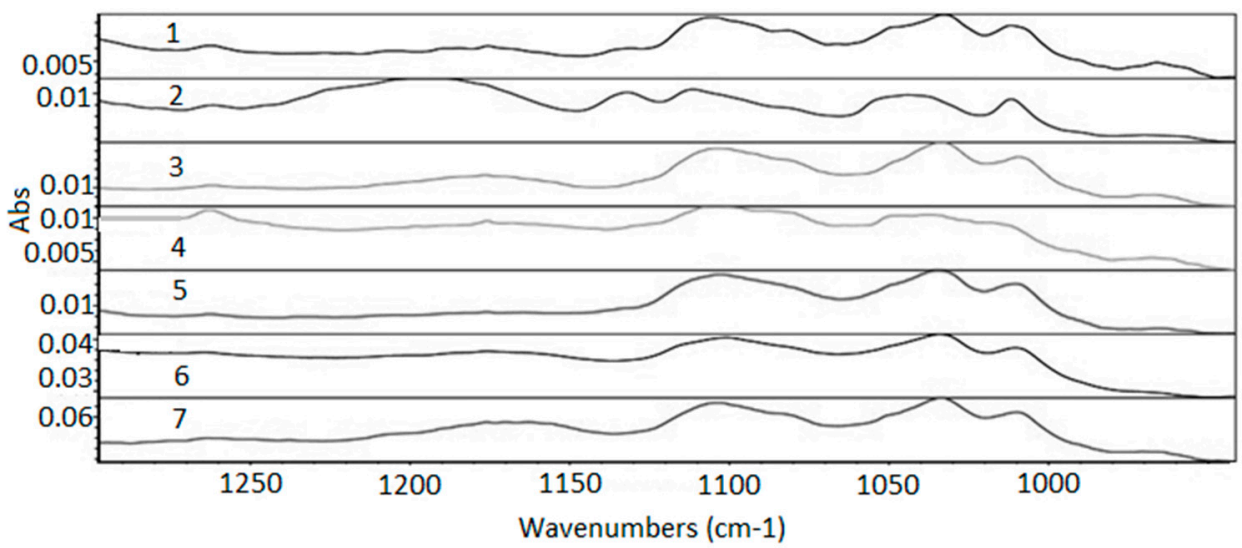

Figure 10. Absorption spectra region from 1300 to $950 \mathrm{~cm}^{-1}$. 1-virgin sample; 2-960 h Xenon arc sample; 3-1639 h Xenon arc sample; 4-2160 h Xenon arc sample; 5-960 h UV fluorescent sample; 6-4380 h UV fluorescent sample; and 7-8760 h UV fluorescent sample.

It can be observed that all the functional groups characteristic of the polymer were preserved showing that the exposures carried out under different conditions did not cause the departure of any functional group and no reaction was also observed.

Variations in samples' absolute absorbance values were observed, probably related to the different conditions that samples were exposed to compared with the virgin sample. The degradations caused by the exposures can indicate small morphological changes in the polymers that did not present a trend. However, greater absolute absorbances can be observed in the total spectrum (region of $600-3100 \mathrm{~cm}^{-1}$ ) for the exposed samples compared with the virgin sample. Moynihan [41] also observed changes in the infrared spectra for the PTFE polymer with different morphologies and related this change to the intensity of the peaks. The intensity of the peaks decreased with the increase in crystallinity caused by the exposure of the samples in different degradation conditions. The changes were not sufficient to cause breaks in the functional group or other reactions and did not follow a trend compared with the virgin sample.

\section{Conclusions}

This manuscript analyzed the behavior of $1.0 \mathrm{~mm}$-thick HDPE virgin geomembrane under exposures to two ultraviolet radiation devices for different exposure times. The characterization of the virgin samples showed property values according to the GRIGM13, with exceptions for stress crack resistance and oxidative induction time values (for 
standard and high-pressure tests), which showed values lower than the minimum required values. The HDPE geomembrane's stress crack resistance is led by the resin's density and molecular weight distribution. The OIT values depend on the quantity and the quality of the geomembrane's additive package.

The MFI is a qualitative test to assess the polymer's molecular weight. The sample under Xenon arc exposure chamber showed a trend to increase the MFI's values during the exposure time. This increasing trend can indicate changes in the polymer's morphology. The sample under UV fluorescent device exposure presented variations among the virgin sample without a trend.

The tensile behavior analysis showed a sample's trend to lose its ductileness, without presenting brittle behavior. The resistance and elongation decrease during the exposure time for the UV fluorescent device exposure was, on average, about $30 \%$.

The samples' OIT test results under both device exposures showed faster antioxidant depletion for the standard OIT test than the high-pressure OIT test. The higher temperature of the standard assay may have contributed to the faster antioxidant depletion. After $8760 \mathrm{~h}$ of exposure, the sample under UV fluorescent device exposure decreased $75 \%$ for the Std. OIT test and 36\% for the HP OIT test. For the Xenon arc exposure chamber, the sample tested demonstrated a decrease of 35\% for the Std. OIT test and $8 \%$ for the HP OIT test after $2160 \mathrm{~h}$ of exposure. For the Std. OIT test results, considering the lower exposure time, the fastest antioxidant depletion occurred for the Xenon arc exposure chamber than the UV fluorescent device exposure.

The samples' DSC curves under heating and cooling presented no differences during the exposure for both devices. The coincident melting and crystallization points obtained can be explained by the predominating disordered molecular material in the endothermic process and the trend to ordinate the polymer's melted molecules in the exothermic process.

The FTIR analysis was carried out for the range of 600 to $4000 \mathrm{~cm}^{-1}$ to check for possible formations, breaks in functional groups, and oxidative reactions. For both exposures the analysis showed that it did not cause any departure from functional groups and no reaction was observed. All functional groups characteristic of the polymer were preserved. Variations in samples' absolute absorbance values were observed, probably related to the different conditions that samples were exposed to compared with the virgin sample. The changes were not sufficient to cause breaks in the functional group or other reactions and did not follow a trend compared with the virgin sample.

Author Contributions: Conceptualization, F.L.L., M.K. and C.A.V.; methodology, F.L.L., M.K., C.A.V. and É.F.d.S.T.; validation, F.L.L., M.K., C.A.V., É.F.d.S.T., J.L.d.S. and M.d.L.L.; formal analysis, F.L.L., M.K., C.A.V. and É.F.d.S.T.; investigation, F.L.L., M.K., C.A.V. and É.F.d.S.T.; resources, F.L.L., M.K. and J.L.d.S.; data curation, F.L.L., M.K., C.A.V. and É.F.d.S.T.; writing-original draft preparation, F.L.L., M.K., C.A.V. and É.F.d.S.T.; writing-review and editing, F.L.L., J.L.d.S. and M.d.L.L.; visualization, F.L.L., M.K., C.A.V., J.L.d.S. and M.d.L.L.; supervision, F.L.L. and J.L.d.S.; project administration, F.L.L. and J.L.d.S.; funding acquisition, F.L.L. and J.L.d.S. All authors have read and agreed to the published version of the manuscript.

Funding: This research received no external funding.

Institutional Review Board Statement: Not applicable.

Informed Consent Statement: Not applicable.

Conflicts of Interest: The authors declare no conflict of interest.

\section{References}

1. Koerner, R.M. Designing with Geosynthetics, 5th ed.; Prentice Hall: Upper Saddle River, NJ, USA, 2005.

2. Rollin, A.R.; Rigo, J.M. Geomembranes-Identification and Performance Testing, 1st ed.; Chapman and Hall: London, UK, 1991.

3. Vertematti, J.C. Manual Brasileiro de Geossintéticos, 2nd ed.; Blücher: São Paulo, Brazil, 2015.

4. Rowe, R.K.; Sangam, H.P. Durability of HDPE Geomembranes. Geotext Geomembr. 2002, 20, 77-95. [CrossRef]

5. Koerner, G.R.; Hsuan, Y.G.; Koerner, R.M. The durability of geosynthetics. In Geosynthetics in Civil Engineering; Sarsby, R.W., Ed.; Woodhead Published Limited: Cambridge, UK, 2007; pp. 36-65. 
6. $\quad$ Kelen, T. Polymer Degradation, 1st ed.; Van Nostrand Reinhold Co.: New York, NY, USA, 1983.

7. Lavoie, F.L.; Kobelnik, M.; Valentin, C.A.; da Silva, J.L. Durability of HDPE geomembranes: An overview. Quim. Nova 2020, 43, 656-667. [CrossRef]

8. Van Santvoort, G. Geotextiles and Geomembranes in Civil. Engineering, 1st ed.; A.A. Balkema: Rotterdam, The Netherlands, 1994.

9. Sharma, H.D.; Lewis, S.P. Waste Containment System, Waste Stabilization and Landfills: Design and Evaluation, 1st ed.; Wiley: New York, NY, USA, 1994.

10. Suits, L.D.; Hsuan, Y.G. Assessing the photo-degradation of geosynthetics by outdoor exposure and laboratory weatherometer. Geotext. Geomembr. 2003, 21, 111-122. [CrossRef]

11. Koerner, R.M.; Hsuan, Y.G.; Koerner, G.R. Freshwater and geosynthetics; A perfect marriage. In Proceedings of the 1st Pan American Conference on Geosynthetics, Cancun, Mexico, 2-5 March 2008.

12. Sahu, A.K.; Sudhakar, K.; Sarviya, R.M. Influence of U.V light on the thermal properties of HDPE/Carbon black composites. Case Stud. Therm. Eng. 2019, 15, 100534. [CrossRef]

13. Jiang, T.; Qi, Y.; Wu, Y.; Zhang, J. Application of antioxidant and ultraviolet absorber into HDPE: Enhanced resistance to UV irradiation. e-Polymers 2019, 19, 499-510. [CrossRef]

14. Reis, R.K.; Barroso, M.; Lopes, M.G. Evolução de cinco geomembranas expostas a condições climáticas em Portugal durante 12 anos. Geotecnia 2017, 141, 41-58. [CrossRef]

15. Martínez-Romo, A.; González-Mota, R.; Soto-Bernal, J.J.; Rosales-Candelas, I. Investigating the Degradability of HDPE, LDPE, PE-BIO, and PE-OXO Films under UV-B Radiation. J. Spectrosc. 2015, 586514. [CrossRef]

16. Mendes, L.C.; Rufino, E.S.; de Paula, F.O.C.; Torres, A.C., Jr. Mechanical, thermal and microstructure evaluation of HDPE after weathering in Rio de Janeiro City. Polym. Degrad. Stab. 2003, 79, 371-383. [CrossRef]

17. Qureshi, F.S.; Amin, M.B.; Maadha, A.G.; Hamid, S.H. Weather-induced degradation of linear low-density polyethylene: Mechanical properties. Polym.-Plast. Technol. Eng. 1989, 28, 649-662. [CrossRef]

18. Rowe, R.K.; Ewais, A.M.R. Ageing of exposed geomembranes at locations with different climatological conditions. Can. Geotech J. 2015, 52, 326-343. [CrossRef]

19. Lavoie, F.L.; Valentin, C.A.; Kobelnik, M.; Lins da Silva, J.; Lopes, M.L. Study of an exhumed HDPE geomembrane used in an industrial water pond: Physical and thermoanalytical characterisations. Results Mater. 2020, 8, 100131. [CrossRef]

20. Lodi, P.C.; Bueno, B.S.; Vilar, O.M. The effects of weathering exposure on the physical, mechanical, and thermal properties of high-density polyethylene and poly (vinyl chloride). Mater. Res. 2013, 16, 1331-1335. [CrossRef]

21. ASTM (American Society for Testing and Materials). ASTM D5199 Standard Test Methods for Measuring the Nominal Thickness of Geosynthetics; ASTM: West Conshohocken, PA, USA, 2019; p. 4.

22. ASTM (American Society for Testing and Materials). ASTM D792 Standard Test Methods for Density and Specific Gravity (Relative Density) of Plastics by Displacement; ASTM: West Conshohocken, PA, USA, 2020; p. 6.

23. ASTM (American Society for Testing and Materials). ASTM D1238 Standard Test Methods for Melt Flow Rates of Thermoplastics by Extrusion Plastometer; ASTM: West Conshohocken, PA, USA, 2020; p. 17.

24. ASTM (American Society for Testing and Materials). ASTM D4218 Standard Test Method for Determination of Carbon Black Content in Polyethylene Compounds by the Muffle-Furnace Technique; ASTM: West Conshohocken, PA, USA, 2020; p. 4.

25. ASTM (American Society for Testing and Materials). ASTM D5596 Standard Test Method for Microscopic Evaluation of the Dispersion of Carbon Black in Polyolefin Geosynthetics; ASTM: West Conshohocken, PA, USA, 2016; p. 3.

26. ASTM (American Society for Testing and Materials). ASTM D6693 Standard Test Methods for Determining Tensile Properties of Nonreinforced Polyethylene and Nonreinforced Flexible Polypropylene Geomembranes; ASTM: West Conshohocken, PA, USA, $2020 ;$ p. 6.

27. ASTM (American Society for Testing and Materials). ASTM D1004 Standard Test Methods for Tear Resistance (Graves Tear) of Plastic Film and Sheeting; ASTM: West Conshohocken, PA, USA, 2021; p. 5.

28. ASTM (American Society for Testing and Materials). ASTM D4833 Standard Test Method for Index Puncture Resistance of Geomembranes and Related Products; ASTM: West Conshohocken, PA, USA, 2020; p. 4.

29. ASTM (American Society for Testing and Materials). ASTM D5397 Standard Test Method for Evaluation of Stress Crack Resistance of Polyolefin Geomembranes Using Notched Constant Tensile Load Test.; ASTM: West Conshohocken, PA, USA, $2020 ;$ p. 7.

30. ASTM (American Society for Testing and Materials). ASTM D3895 Standard Test Method for Oxidative-Induction Time of Polyolefins by Differential Scanning Calorimetry; ASTM: West Conshohocken, PA, USA, 2019; p. 7.

31. ASTM (American Society for Testing and Materials). ASTM D5885 Standard Test Method for Oxidative Induction Time of Polyolefin Geosynthetics by High-Pressure Differential Scanning Calorimetry; ASTM: West Conshohocken, PA, USA, $2020 ;$ p. 7.

32. GRI (Geosynthetic Research Institute). GRI-GM13 Test Methods, Test Properties and Testing Frequency for High. Density Polyethylene (HDPE) Smooth and Textured Geomembranes; GRI: Folsom, PA, USA, 2021; p. 11.

33. ASTM (American Society for Testing and Materials). ASTM D7238 Standard Test Method for Effect of Exposure of Unreinforced Polyolefin Geomembrane Using Fluorescent UV Condensation Apparatus; ASTM: West Conshohocken, PA, USA, $2020 ;$ p. 4.

34. ASTM (American Society for Testing and Materials). ASTM G155 Standard Practice for Operating Xenon Arc Light Apparatus for Exposure of Non-Metallic Materials; ASTM: West Conshohocken, PA, USA, 2013; p. 11.

35. Hsuan, Y.G.; Koerner, R.M. Antioxidant depletion lifetime in high density polyethylene geomembranes. J. Geotech. Geoenviron. Eng. 1998, 124, 532-541. [CrossRef] 
36. Rowe, R.K.; Islam, M.Z.; Hsuan, Y.G. Leachate chemical composition effects on OIT depletion in an HDPE geomembranes. Geosynth. Int. 2008, 15, 136-151. [CrossRef]

37. Noval, A.M.; Blanco, M.; Castillo, F.; Leiro, A.; Mateo, B.; Zornberg, J.G.; Aguiar, E.; Torregrosa, J.B.; Redón, M. Long-term performance of the HDPE geomembrane at the "San Isidro" reservoir. In Proceedings of the 10th International Conference on Geosynthetics, Berlin, Germany, 21-25 September 2014.

38. Colthup, N.B.; Daly, L.H.; Wiberley, S.E. Introduction to Infrared and Raman Spectroscopy, 3rd ed.; Academic Press: Cambridge, MA, USA, 1990

39. Koenig, J.L. Spectroscopy of Polymers, 2nd ed.; American Chemical Society: Washington, DC, USA, 1999.

40. Stuart, B. Infrared Spectroscopy Fundamentals and Applications, 1st ed.; John Wiley and Sons: New York, NY, USA, 2004.

41. Moynihan, R. The molecular structure of perfluorocarbon polymers. Infrared studies on polytetrafluoroethylene. J. Am. Chem. Soc. 1959, 81, 1045-1050. [CrossRef] 